\title{
MOTIVATION AND LEARNING STYLE: DO THEY CORRELATE WITH LANGUAGE PROFICIENCY?
}

\author{
Udin Kamiluddin \\ udinkamiludin@syekhnurjati.ac.id \\ IAIN Syekh Nurjati
}

\begin{abstract}
This paper discusses the issues of motivational orientation, learner types and their relationship with English Language Proficiency among the students of semester one in the academic year 2018 / 2019 at the State Institute of Islamic Studies Syekh Nurjati, Cirebon. It is a survey research. The data were obtained through the questionnaires i.e. the Attitude / Motivation Test Battery (AMTB) developed by R.C Gardner, and "How do you learn best?" adapted from K. Willing's model. And the Standardized Test of English was designed adopting the TOEFL model. The statistical software such as SPSS was employed to analyze the data. The results show most of the participants are instrumentally motivated learner and are communicative as well as teacheroriented types, and majority of them are of medium level of English Language Proficiency. Furthermore, the findings reveal that an integrative motivated learners scored better than instrumentally motivated learners in English Language Proficiency Test. This means motivation correlates with English Language Proficiency. Whereas, learning style does not correlate with English Language Proficiency. However, the result of correlation test confirms the $r$ score $(0.456)$ is more than $\mathrm{t}$ table score $(0.2441)$; which means the H0 hypothesis is rejected. Thus, Motivation and Learning Style correlate with English Language Proficiency. The findings led to conduct further research on motivating students as to improve their level of English language proficiency.
\end{abstract}

Keywords: Language proficiency; learning style; motivation

\section{BACKGROUND}

Educators and researchers have been recognizing the two important factors that affect the process of learning and teaching. They are institutional and individual factors. The institutional factors include philosophy of teaching and program, school's organization culture and how it maintains the quality of teaching and learning, curriculum, teacher's competence and teaching strategies, the size and environment of the class, the learning resources (for instance libraries, laboratories and information technology) available and used, learning environment ( in and outside the classroom) that supports intra and extra-curricular activities, learning assessment process and feedback. Whereas, 
the learner's factor involve, attitude, interest, aptitude, desire, effort, motivation, orientation to learn, approaches to learning, learning style, learning strategy, learner's views on the school program, order of language study and bilingualism, study habits, gender, age, intelligence, anxiety, and in the wider context social environment that surrounds the school contribute significantly to learning and teaching process. (Chiew Fen $\mathrm{Ng}$ and Poh Kiat Ng. 2015: 76; Bc. Lenka Svobodová, 2015: 10-18; Oletic, A. and Ilic, N. 2014: 125; Xiang Yang, 2012: 13-22; Markwell, 2003: 1-2; Richards, 2001: 373-412; R.C. Gardner, 1985: 178-182; Dornyei, 1998: 117-135; Kassing, 2011: 25; Hahn, 1996: 76-77; Basri, 2015: 51-57; Suyono and Haryanto, 2015: 176-198).

Of those factors, motivation and learning style have much got attention from researchers. Numerous studies reveal that when students are well-motivated and their learning preferences are proportionally accommodated, they likely get better improvement in their studies. Similarly, in the case of teaching and learning English as second or foreign language.

Motivated language learners may become creative learners on the language they are learning (Kimura, Nakata \& Okumura, 2001: 35). Specifically, they suggest that motivation of a learner can indicate the degree of success in second/foreign language attainment. Therefore motivation is crucial to the success (Dornyei, 1994), and may affect the degree of success in second/foreign language learning (Dornyei, 1998: 117). Xiang Yang (2012: 13-22) reveals that there is significant correlation between English proficiency and positive attitude towards learning English, for both instrumental (Gardner, 1960; Brown, 2000) and integrative motivation (Nida, 1956; Liu, 2007; Lo Castro, 2001). Intrinsic and extrinsic motivation determine the success of learners at all stages of their education (Chiew Fen Ng and Poh Kiat Ng. 2015; (Kimura, Y. et al); including learning English as a Foreign Language (Oletic and Ilic, 2014).

Gardner and Lambert indicated in their studies among the Philippines learners of English, that learners with a higher integrative orientation are likely to be more proficient than those who are instrumentally motivated. However, as they argued themselves, that "when there is a vital need to master a second language, the instrumental approach is very effective, perhaps more so than the integrative". Lukmani's research on learners of English in India showed that instrumental motivation and proficiency in English are strongly correlated. Similarly, Littlewood says that most learners perceive English as an International language. As a result, it is not surprising if integrative attitudes are not so significant as learner's instrumental reasons for acquiring the language (Cora Hahn, 1996: 76-77).

On the other side, several studies have provided evidence on the positive effect of accommodating learner's diversity (Sharp, 2004: 1). Optimal learning occurs when students' and teachers' expectation of each other are mutually respected through establishment of agreement between them on the subjects matter and why they need to learn them. (Kasaian and Ayatollahi, 2010: 131). Parallel with this is what Zhenhui (2001: 1-5) stated that teachers' knowledge and understanding about his/her students' preferred ways of learning help them create effective teaching. The students can learn more effectively when their learning styles are accommodated proportionally. In other words, students will be more successful in their learning if the teaching strategy matches the students' particular aptitude for learning and if they are motivated. Matching teaching 
style with students' learning style improve students achievement, class performance and motivation to learn, significantly. It contributes to more effective learning and significant academic progress (Ho, 1999: 53), and is the foundation of a truly modern education (Dunn, 1984: 10). However, students who are adaptable to teacher's teaching strategy will be easier to process learning and more satisfied than those who are not (She: 2003: 609).

The foregoing discussion indicates the significance of motivation and learning style in learning and teaching to succeed, and the provision of academic documents on the relations of motivation and learning style with student's academic achievement has become a necessity.

\section{METHOD}

This is a quantitative research. Specifically, it is a survey research using correlational approach: bivariate correlation that describes the correlation between two variables, they are motivation and learning style with language proficiency (Emzir, 2015: 48). It involves data collection procedures that result primarily in numerical data which is then analyzed primarily by statistical methods. Typical example: survey research using a questionnaire, analyzed by statistical software such as SPSS (Dornyei, 2007: 42). Survey research provides quantitative or numeric description of trends, attitudes, or opinions of population by studying a sample of that population. It includes cross-sectional and longitudinal studies using questionnaire or structured interviews for data collection, with the intent of generalizing from a sample to a population (Creswell, 2009: p. 12).

This research is amied to investigate which motivation and learning style do the students exhibit in the EFL classroom and to what extent do motivation and learning style correlate with language proficiency. To prove these purposes, the reseacher defines the hypothesis H0 (null hypothesis): Motivation and learning style do not correlate with language proficiency.

The accessed population of this research includes the students of semester one at IAIN Syekh Nurjati Cirebon in the Academic Year 2018/2019. Whereas the sample involves 65 students in the ELT Dept. Both male and female students participated in this inquiry. Sampling technique uses stratified sampling.

Research instruments used in this study are "Attitude / Motivation Test Battery" (AMTB) questionnaire, "How do you learn best" questionnaire, and Standardized Test of English. The AMBT questionnaire was developed by Robert C. Gardner (1985, pp. 176182) in his book "Social Psychology and Second Language Learning the Role of Attitudes and Motivation". It consists of a number of statements in which some people agree and others disagree. These items are used to measure Motivational Intensity, Desire to Learn French, and Orientation Index. The measurement technique uses Likert Scale model.

In this context, the researcher uses a part of the AMBT questionnaire (49 items) to measure the students' interest in foreign languages (10 items); attitude towards learning English (10 items); integrative orientation / motivation (4 items), instrumental orientation / motivation (4 items); motivational intensity (10 items); desire to learn English (10 items; and orientation index (1 item). In addition to this, the researcher is generating 15 motivating factors in the EFL classroom were adapted from several theoretical bases. 
The questionnaire "How do you learn best" is adapted from Willing's model (1988: 106). It consisted of 30 questions originally, but then, modified purposely by the researcher to 24 items. There are four types of learners identified by Willing through this questionnaire, namely analytical learners, communicative learners, concrete learners and teacher-oriented learners. All the questionnaires are translated into Indonesian language for clear understanding among the respondents. The Standardized Test of English is designed by the researcher in accordance with the level of respondents. The test is written test following the TOEFL format. It consists of 20 questions.

\section{Data Collection}

The AMBT questionnaire of 49 items is used to get the data on the students' interest in foreign languages (10 items); attitude towards learning English (10 items); integrative orientation / motivation (4 items), instrumental orientation / motivation (4 items); motivational intensity (10 items); desire to learn English (10 items); and orientation index (1 item). In addition to this, another 15 items were adapted from several theoretical bases are generated to explore motivating and factors in the EFL classroom.

The questionnaire "How do you learn best" developed by Willing (1988: 106) is used to obtain the data of the students' learning style preferences (analytical learner, communicative learner, concrete learner, and teacher-oriented learner). Whereas Standardized Test of English is run to measure language proficiency among the respondents.

\section{Data Analysis}

The data obtained through the AMBT questionnaire using the Likert Scale format are then, analyzed by SPSS version 20 .

The data on the students' learning style preferences are analyzed by adding up the scores of the subjects obtained under each category of questions. Thus, each subject had four scores. The highest score among the four scores obtained indicated what type of learner a subject belonged to. In cases where the subjects obtained two or more tied scores, they were not categorized into any learner type. They are called the "mixed type" or "combined type".

Pearson correlation analysis is run to examine the relationships between the variables of motivation and learning style with language proficiency.

\section{FINDINGS AND DISCUSSION}

The questionnaire that consists of eight statements were administered to investigate either the participants have integrative or instrumental motivation. The integrative and instrumental orientation are originally of the 7-point Likert Scale model developed by Gardner (1985). It was then, modified into a 5 point-scale, stretching from 'strongly agree' to 'strongly disagree'. 
The data were computerized and analyzed by using SPSS. Descriptive statistics were presented to illustrate the types of motivation in which the participants in this study exhibit.

Chart 1. Distribution of Motivation among the total of 65 participants

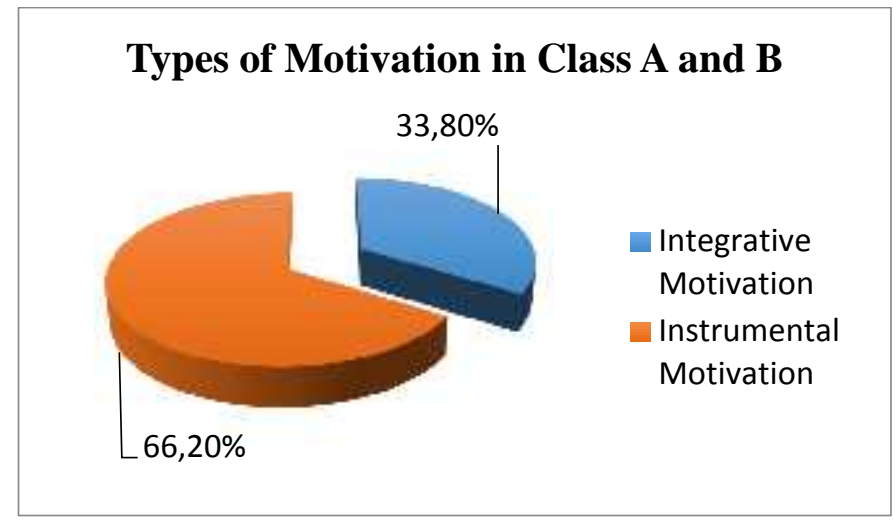

The above chart illustrates a sum of 22 or $33.8 \%$ participants are categorized as integrative motivated learner. Whereas, another 43 or $66.2 \%$ have instrumental motivation. Hence, it can be said that majority of the participants are instrumentally motivated learner.

Chart 2. Distribution of Learning Style among the total of 65 participants

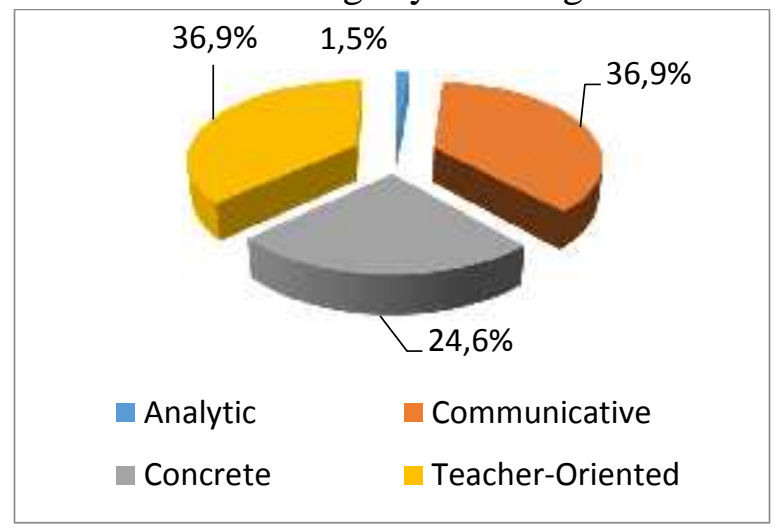

Overall, the chart 2 tells that 24 or $36.9 \%$ participants are Communicative Learner type, and another 24 or $36.9 \%$ participants are Teacher-Oriented Learner type. It is, therefore, can be concluded that the participants are equally dominated by both types, i.e. Communicative Learner type and Teacher-Oriented Learner type.

Chart 3. Distribution English Language Proficiency Level among the total of 65 participants 


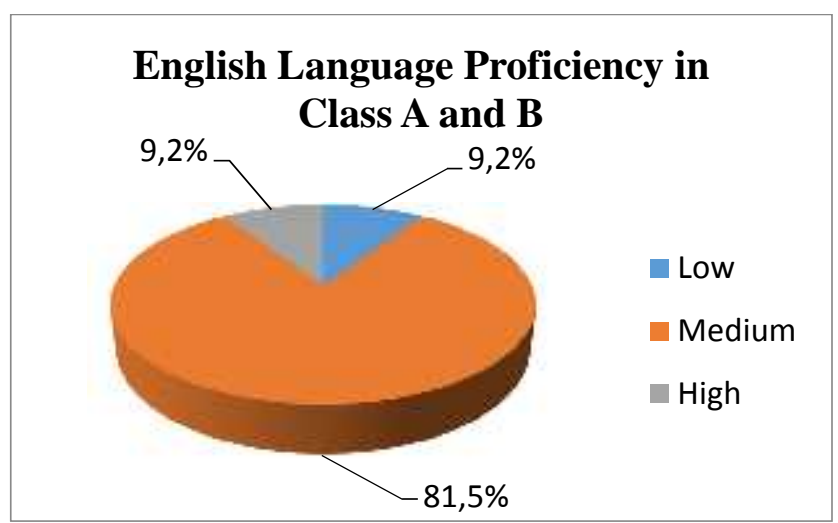

Based on the Test of English Language Proficiency, a sum of 53 or $81.5 \%$ of the participants in this study obtained medium score. Thus, their level of English proficiency is classified as the medium level. In another words, most of the participants are placed at the intermediate level of English Language Proficiency.

Table 1. The Correlation of Motivation with English Language Proficiency

\begin{tabular}{|c|c|c|c|c|c|c|c|c|c|}
\hline \multirow{4}{*}{ No } & \multirow{4}{*}{$\begin{array}{c}\text { Types of Motivation in } \\
\text { Class A and B }\end{array}$} & \multicolumn{6}{|c|}{ English Language Proficiency in } & \multirow{2}{*}{\multicolumn{2}{|c|}{ Total }} \\
\hline & & \multicolumn{6}{|c|}{ Class $A$ and $B$} & & \\
\hline & & \multicolumn{2}{|c|}{ Low } & \multicolumn{2}{|c|}{ Medium } & \multicolumn{2}{|c|}{ High } & \multirow[b]{2}{*}{$\mathbf{N}$} & \multirow[b]{2}{*}{$\%$} \\
\hline & & $\mathbf{N}$ & $\%$ & $\mathbf{N}$ & $\%$ & $\mathbf{N}$ & $\%$ & & \\
\hline 1. & Integrative Motivation & 0 & 0 & 16 & 72,7 & 6 & 27,3 & 22 & 100 \\
\hline 2. & Instrumental Motivation & 6 & 14 & 37 & 86 & 0 & 0 & 43 & 100 \\
\hline & Total & 6 & 9,2 & 53 & 81,5 & 6 & 9,2 & 65 & 100 \\
\hline
\end{tabular}

According to the table 1, the following points may be stated:

1. Of the total 65 participants, it is found that 22 participants have an Integrative Motivation and the rest of 43 participants are Instrumentally Motivated.

2. Of the 22 participants who have an Integrative Motivation, none or $0 \%$ of them obtained "low" score in the English Language Proficiency Test. Whereas 16 or 72.7 $\%$ of them obtained "medium" score, and 6 or $27.3 \%$ of them obtained "high" score.

3. Of the 43 participants who have an Instrumental Motivation, it is found that 6 or 14 $\%$ of them obtained "low" score in the English Language Proficiency Test. Whereas 37 or $86 \%$ of them obtained "medium" score, none of them obtained "high" score.

4. Hence, it may be said that those participants who have an Integrative Motivation are better than those who are Instrumentally Motivated learner in terms of English Language Proficiency.

In order to determine the correlation of Motivation with English Language Proficiency, Spearman's rho model was employed. 


\begin{tabular}{|c|c|c|c|c|}
\hline \multicolumn{5}{|c|}{ Correlations } \\
\hline & & & Types of & English \\
\hline & & & Motivation & Language \\
\hline & & & & Proficiency \\
\hline \multirow{6}{*}{ Spearman's rho } & \multirow{3}{*}{$\begin{array}{l}\text { Types of } \\
\text { Motivation }\end{array}$} & Correlation Coefficient & 1.000 & $.454^{* *}$ \\
\hline & & Sig. (2-tailed) & . & .000 \\
\hline & & $\mathrm{N}$ & 65 & 65 \\
\hline & English & Correlation Coefficient & $.454^{* *}$ & 1.000 \\
\hline & Language & Sig. (2-tailed) & .000 & . \\
\hline & Proficiency & $\mathrm{N}$ & 65 & 65 \\
\hline
\end{tabular}

The result of the SPPS analysis above indicates the score of Spearman's rho between the Types of Motivation and English Language Proficiency is 0,454. The correlation score ranges from 0,400 to 0,599 ; which means that there is significant relationship between the Types of Motivation and English Language Proficiency.

Having got the Correlation Coefficient score, it is necessary to examine the hypothesis to confirm whether the correlation is significant or not. Hypothesis test can be identified through significance score comparison, i.e.

If the significance score is $>0.05$ the $\mathrm{H} 0$ is accepted.

If the significance score is $<0.05$ the $\mathrm{H} 0$ is rejected.

The result of correlation test above shows the significance score is 0.000 . Since the significance score is less than 0.05 , therefore, the $\mathrm{H} 0$ hypothesis is rejected. It means Motivation correlates with English Language Proficiency.

Table 2. The Correlation of Learning Style with English Language Proficiency

$$
\text { English Language Proficiency in }
$$

\begin{tabular}{|c|c|c|c|c|c|c|c|c|c|}
\hline \multirow{3}{*}{ No } & \multirow{3}{*}{$\begin{array}{c}\text { Learning Style in } \\
\text { Class A and B }\end{array}$} & \multicolumn{6}{|c|}{ Class $A$ and $B$} & \multicolumn{2}{|c|}{ Total } \\
\hline & & \multicolumn{2}{|c|}{ Low } & \multicolumn{2}{|c|}{ Medium } & \multicolumn{2}{|c|}{ High } & \multirow[b]{2}{*}{$\mathbf{N}$} & \multirow[b]{2}{*}{$\%$} \\
\hline & & $\mathbf{N}$ & $\%$ & $\mathbf{N}$ & $\%$ & $\mathbf{N}$ & $\%$ & & \\
\hline 1. & Analytic & 0 & 0 & 1 & 100 & 0 & 0 & 1 & 100 \\
\hline 2. & Communicative & 1 & 4,2 & 21 & 87,5 & 2 & 8,3 & 24 & 100 \\
\hline 3. & Concrete & 2 & 12,5 & 12 & 75 & 2 & 12,5 & 16 & 100 \\
\hline 4. & Teacher-Oriented & 3 & 12,5 & 19 & 79,2 & 2 & 8,3 & 24 & 100 \\
\hline & Total & 6 & 9,2 & 53 & 81,5 & 6 & 92 & 65 & 100 \\
\hline
\end{tabular}


As shown in the table 2, it was found that:

1). Of the 65 participants, only one of them is Analytic Learner Type, 24 of them is Communicative Learner Type, 16 of them is Concrete Learner Type, and another 24 of them is Teacher-Oriented Learner Type. Thus, most of the participants in this study belong to Communicative and Teacher-Oriented types.

2). Of the 65 participants one or $1.5 \%$ of them is Analytic Learner Type who obtained "medium" score.

3). Of the 24 participants who are Communicative Learner Type one or $4.2 \%$ of them obtained "low" score, 21 or $87.5 \%$ of them obtained "medium" score", and 2 or 8.3 $\%$ of them obtained "high" score. In short, most of the participants in this research have medium level of English Language Proficiency.

4). Of the 16 participants who are Concrete Learner Type two or $12.5 \%$ of them obtained "low" score, 12 or $75 \%$ of them obtained "medium" score", and 2 or $12.5 \%$ of them obtained "high" score. In short, most of the participants who belonged to the Concrete Learner Type in this research have medium level of English Language Proficiency.

5). Of the 24 participants who are Teacher-Oriented Learner Type three or $12.5 \%$ of them obtained "low" score, 19 or $79.2 \%$ of them obtained "medium" score", and 2 or $8.3 \%$ of them obtained "high" score. In short, most of the participants who belonged to the Teacher-Oriented Learner Type in this research reach medium level of English Language Proficiency.

6). Overall, the participants are placed at the intermediate level of English Language Proficiency.

In order to determine the correlation of Learning Style with English Language Proficiency, Spearman's rho model was employed.

\begin{tabular}{|c|c|c|c|c|}
\hline \multicolumn{5}{|c|}{ Correlations } \\
\hline & & & Learning style & $\begin{array}{c}\text { English } \\
\text { Language } \\
\text { Proficiency }\end{array}$ \\
\hline \multirow{6}{*}{ Spearman's rho } & \multirow{3}{*}{ Learning style } & Correlation Coefficient & 1.000 & -.081 \\
\hline & & Sig. (2-tailed) & . & .520 \\
\hline & & $\mathrm{N}$ & 65 & 65 \\
\hline & English & Correlation Coefficient & -.081 & 1.000 \\
\hline & Language & Sig. (2-tailed) & .520 & . \\
\hline & Proficiency & $\mathrm{N}$ & 65 & 65 \\
\hline
\end{tabular}

The result of the SPPS analysis above indicates the score of Spearman's rho between the Learning Style and English Language Proficiency is -0,081. The correlation score indicates negative score. It means that the relation between Learning style and English Language Proficiency is negative. 
Having got the Correlation Coefficient score, it is necessary to examine the hypothesis to confirm whether the correlation is significant or not. Hypothesis test can be identified through significance score comparison, i.e.

If the significance score is $>0.05$ the $\mathrm{H} 0$ is accepted.

If the significance score is $<0.05$ the $\mathrm{H} 0$ is rejected.

The result of correlation test above shows the significance score is 0.520 . Since the significance score is more than 0.05, therefore, the H0 hypothesis is accepted. It means Learning Style does not correlate with English Language Proficiency.

In order to determine the correlation of Motivation and Learning Style with English Language Proficiency, Model Summary was employed.

Table 3. The Correlation of Motivation and Learning Style with English Language Proficiency

\begin{tabular}{llccc}
\hline \multicolumn{5}{c}{ Model Summary } \\
\hline Model & $\mathrm{R}$ & R Square & $\begin{array}{c}\text { Adjusted R } \\
\text { Square }\end{array}$ & $\begin{array}{c}\text { Std. Error of the } \\
\text { Estimate }\end{array}$ \\
\hline 1 & $.456^{\mathrm{a}}$ & .208 & .182 & .39155 \\
\hline a. Predictors: (Constant), Learning style & , Types of Motivation \\
\hline
\end{tabular}

The result of the SPPS analysis above indicates the score of $\mathrm{R}$ between Motivation and Learning style with English Language Proficiency is 0.456. The correlation score ranges from 0.400 to 0.599 ; which means that the relationship between Motivation and English Language Proficiency is sufficient.

Having got the Correlation Coefficient score, it is necessary to examine the hypothesis to confirm whether the correlation is significant or not. Hypothesis test can be identified through significance score comparison, i.e.

If $\mathrm{r}$ score is $<\mathrm{t}$ table, the $\mathrm{H} 0$ is accepted.

If $\mathrm{r}$ score is $>\mathrm{t}$ table, the $\mathrm{H} 0$ is rejected.

The total number of participants in this research is 65 . Therefore, $\mathrm{df}$ score is $=65-2$ $=63$. Consequently, $\mathrm{t}$ table score is 0.2441 .

The result of correlation test above shows the $\mathrm{r}$ score $(0.456)$ which is more than $\mathrm{t}$ table score (0.2441). Thus, the H0 hypothesis is rejected. It means Motivation and Learning Style correlate with English Language Proficiency. 


\section{CONCLUSION}

This research was conducted to discover the motivational orientation and the learning style of the students at the IAIN Syekh Nurjati, Cirebon, especially those who are enrolled at the ELT Department. The results show general picture and common phenomenon that prevail among the Indonesian students. Most of the students who took part in this study are instrumentally motivated learner and are communicative as well as teacher-oriented types. The latter type was similar to that of the researcher's findings in 2016 at the same educational institution. With regard to the level of English Language Proficiency, majority of the participants are of medium level. The level which needs special attention to be addressed in the future.

Moreover, the findings of this inquiry reveal that those participants who possess an integrative motivation are, to a certain degree, better than those who are instrumentally learner in terms of the score of English Language Proficiency. This means the independent variable of motivation correlates with the dependent variable of English Language Proficiency. Whereas, the variable of Learning Style does not correlate with the variable of English Language Proficiency. This point is subject to further research. However, when motivation and learning style are analyzed all together with English Language Proficiency by using the summary model, it shows the relationship between them.

The result of correlation test confirms the $\mathrm{r}$ score $(0.456)$ is more than t table score (0.2441); which means the H0 hypothesis is rejected. Thus, Motivation and Learning Style correlate with English Language Proficiency.

In short, this study has provided answers to all research questions addressed earlier, its hypothesis, and supports the findings of the previous studies, such as Gardner and Lambert who indicated in their studies among the Philippines learners of English, that learners with a higher integrative orientation are likely to be more proficient than those who are instrumentally motivated.

Another research was conducted by Peipei Li \& Guirong Pan (2009) on The Relationship between Motivation and Achievement: A Survey of the Study Motivation of English Majors in Qingdao Agricultural University. Their findings reveal that the instrumentally motivated students achieved both high and low scores in English, whereas the integratively motivated learners achieved higher than those who have an instrumental motivation.

However, the present study contradicts the findings of some other researchers. Lukmani's research on learners of English in India showed that instrumental motivation and proficiency in English are strongly correlated. Similarly, Littlewood says that most learners perceive English as an International language. As a result, it is not surprising if integrative attitudes are not so significant as learner's instrumental reasons for acquiring the language (Cora Hahn, 1996). On the other side, Yazdan Choubsazy and Yassaman Choubsazy have shown in their research that the Iranian university students are both instrumentally and integratively motivated (2014: 392397). 
Finally, the findings of this inquiry, i.e. the students' motivation, the level of their English Language Proficiency, and their individual diversity needs better attention at the institutional level.

\section{REFERENCES}

Barker, M. Understanding Motivation: A Review of Relevant Literature. Carleton papers in Applied Language Studies. Downloaded on 20 Oct. 2017 through google.scholar.go.id.

Basri, H., (2015), Paradigma Baru Sistem Pembelajaran, Bandung: Pustaka Setia.

Lenka, S. (2015). Factors Affecting the Motivation of Secondary School

Students to learn the English Language, unpublished Diploma Theses at Masyarik University.

Brown, B. L. (2003). Teaching Style vs Learning Style. ERIC (Educational Resources Information Centre). Columbus.

Brown, H. D. (2000). Principles of language learning and teaching. New York, Pearson Education

Chiew F. (2015). A Review of Intrinsic and Extrinsic Motivations of ESL Learners, International Journal of Languages, Literature and Linguistics, Vol. 1, No. 2, June.

Coubsaz, Y. \& Yassaman Choubsaz (2014). Motivational Orientation and EFL Learning:

A Study of Iranian Undergratuate Students, Procedia Social and Behavioral Sciences, 98. 392-397

Cohen. L. et al (2007). Research Methods in Education. New York: Routledge.

Creswell, J. W. (2009). Research Design: Qualitative, Quantitative, and Mixed Methods Approaches. Los Angeles: SAGE Publications, Inc.

Dembo, M. H. (2004). Motivation and Learning Strategies for College Students. New Jersey: Lawrence Erlbaum Associates.

Dörnyei, Z. (1998). Motivation on second and foreign language learning. Language Teaching, 31:3, 117-135.

Dörnyei, Z. (2007). Research Methods in Applied Linguistics: Quantitative, Qualitative, and Mixed Methods. Oxford: Oxford University Press.

Dunn, R., (1984). Matching Teaching and Learning Styles. Theory into Practice. Winter, Vol. 23, No. 1, 10-19.

Emzir, (2015). Metodologi Penelitian Pendidikan. Jakarta: Rajawali Pers.

Hahn, C. in Thomas Kral (ed.) (1996). Dealing with Variables in the Language Classroom, Teacher Development Making the Right Moves, pp. 76-77, Washington D.C. United States Information Agency,

Ho, B. (1999). Learning style preferences of students learning English. Perspectives. Vol.

11: 53 (Autumn). City University of Hong Kong. Hong Kong Journals online. 
Kassaian, Z. and Ayatollahi, M. A (2010). Teaching Styles and Optimal Guidance in English Language Major. Quarterly Journal of Research and Planning Development in Higher Education (2010). No. 55, 2010, pp. 131-152. Isfahan.

Kimura, Y. et al. Language Learning Motivation of EFL Learners in Japan-A CrossSectional Analysis of Various Learning Milieus, JALT Journal, downloaded on 10 October, 2017 through google scholar.go.id

Lang, H. R. and Evans, D. N. (2006). Models, Strategies, and Methods for Effective Teaching. Boston:Pearson Education, Inc. Markwell, D. (2003). Improving Teaching and Learning in Universities, B-Heart News, 18, 1-2.

Nunan, D. (1999). Second Language Teaching \& Learning. Massachusetts: Heinle and Heinle.

Oletic, A. and Ilic, N. (2014). Intrinsic and Extrinsic Motivation for Learning English as a Foreign Language, ELTA Journal • December• Volume 2, No. 2.

Peipei Li \& Guirong Pan (2009). The Relationship between Motivation and Achievement: A Survey of the Study Motivation of English Majors in Qingdao Agricultural University, English Language Teaching, Vol. 2, No. 1. www.ccsnet.org/journal.html

Pritchard, A. (2009). Ways of Learning: Learning Theories and Learning Styles in the Classroom. Oxon OX.: Routledge.

Putinseva, T. (2006). The Importance of Learning Styles in ESL/EFL. The Internet TESL Journal, Vol. XII, No. 3, March. http://itesl.org/

Rachmania B. (2011). Perceptions of Motivational Teaching Strategies in an EFL Classroom: The case of a class in a private university in Indonesia, unpublished thesis at Victoria University of Wellington.

R.C. Gardner and P.D. MacIntyre (1991). An Instrumental Motivation in Language Study: Who says it is not effective? Cambridge: Cambridge University Press.

Reid, J. (Ed.) (1998). Understanding Learning Styles in the Second Language Classroom. USA: Prentice Hall Regents.

Richards, J.C. (2001), Program Factors in Effective Foreign and Second Language Teaching, Journal of South East Asian Education, 2 (2), 373-412.

Sukardi (2003). Metodologi Penelitian Pendidikan. Jakarta: Bumi Aksara.

Sullivan, M. A Study of Motivation in the EFL Classroom, downloaded on 10 October 2017 from

http://citeseerx.ist.psu.edu/viewdoc/download?doi=10.1.1.555.4348\&rep=re p1\&type $=$ pdf.

Suyono dan Hariyanto, (2015), Implementasi Belajar dan Pembelajaran, Bandung: Rosda Karya.

Touré-Tillery, M. and Fishbach, A., (2014). How to Measure Motivation: A Guide for the Experimental Social Psychologist, Social and Personality Psychology Compass 8/7: 328-341.

Willing, K. (1988). Learning Styles in Adult Migrant Education. Adelaide. National Curriculum Resource Centre. 
Xiang Y. (2012). Attitude and Motivation in 12 Learning among UM Master Students, International Journal of Management and Sustainability 1(1):13-22

Zhenhui, R. (2001). Matching Teaching Styles with Learning Styles in East Asian Context. The Internet TESL Journal, Vol. VII, No. 7, July 2001, retrieved from

http://iteslj.org?Techniques/Zenhui TeachingStyles.html on 3 February 2008.

Zareian, G. and Hojat Jodaei (2015). Motivation in Second Language Acquisition: A State of the Art Article, International J. Soc. Sci. \& Education, Vol. 5. Issue 2 . 